The operative technique is well described with clear diagrams. There are interesting sections on congenital abnormalities and basic biomechanics.

This book is recommended to all orthopaedic and general surgeons and their trainees who deal with amputation work. The surgeons, limb-fitting surgeons and research workers at Roehampton are to be commended on producing this fine volume.

\section{English for Doctors and Nurses}

By Joy Parkinson. Pp. 124. Evans, London, 1978. $£ 1.95$.

Doctors and nurses from overseas may need a refresher course in colloquial English when arriving here to do TRAB. This book is designed for individual use and also for groups or classes with a teacher. It picks out usage of tenses and prepositions and other common problems which immigrants find difficult. Dr Eric Beck is to be congratulated on making the medicine modern. The photographs could have been more explicit. Radiologists would not approve of the consultant with the elegant cuff links and white rose in buttonhole touching a chest X-ray with the open end of his pen.
The Molecular Biology of Animal Viruses

Volume 2. Edited by Debi Prosad Nayak. Pp. 480, illustrated. Marcel Dekker, New York and Basle, 1978 $\$ 45.00 ; \$ 25.00$ for orders of 5 or more copies (U.S.A. ando Canada only).

The first volume of this work, which was devoted to RNA viruses, virus architecture and interferon, was published in 1977 and was reviewed in this journal (PMJ, 54, 293)? Volume 2 contains five chapters which are extensive reviews of the molecular biology of the major groups of DNA viruses. It is inevitable, with such a fast-moving discipline, that further developments have occurred since these chapters were written. Consequently, two extra sections have beencw included which summarise the latest work in the adenovirus? and herpesvirus fields. The chapter on poxviruses appear rather outdated, but the results of DNA analysis of viruses 3 in this group have only very recently appeared in the literature. The second volume contains the subject index for both volumes and also a comprehensive author index. Taken together, the two volumes provide a most valuable reference source of a rather specialized nature, and they are a significant addition to the virological literature. 